\title{
Occurrence and susceptibilities to disinfectants of Cryptococcus neoformans in fecal droppings from pigeons in Bangkok, Thailand
}

\author{
Prathomporn KRANGVICHAIN ${ }^{1)}$, Waree NIYOMTHAM ${ }^{1)}$ and Nuvee PRAPASARAKUL ${ }^{1) *}$ \\ ${ }^{1)}$ Department of Veterinary Microbiology, Faculty of Veterinary Science, Chulalongkorn University, Bangkok 10330, Thailand
}

(Received 14 October 2015/Accepted 6 November 2015/Published online in J-STAGE 22 November 2015)

\begin{abstract}
Cryptococcus neoformans is an opportunistic pathogenic yeast that causes meningoencephalitis and deep skin dermatitis in humans and animals. A hygienic strategy using disinfectants on environmental samples can reduce the risk to the public. The objectives were to survey the distribution of C. neoformans in pigeon fecal droppings collected in 11 districts in Bangkok during 2011-2012 and to evaluate the efficacy of three commercial disinfectant products (based on potassium monopersulfate, sodium hypochlorite and quaternary ammonium compounds, respectively). These were evaluated against pure C. neoformans and yeasts resuspended in sterile pigeon feces using the dilution-neutralization method [Europäische NORM (EN) 1656]. In total, 18 of 164 (11\%) samples were positive for C. neoformans. These came from only three of the 11 districts, with a prevalence of between 13-56\%. Using multiplex PCR, serotype A was the sole group found. For all disinfectants, C. neoformans mixed in feces was tolerated at a higher dose and time exposure than pure isolates. The most effective disinfectant in this study was a $0.12 \%$ quaternary ammonium compound that could rapidly eradicate the yeasts mixed in feces. This finding highlights the occurrence and distribution of $C$. neoformans in the capital city of Thailand and the need to prolong the duration of exposure to disinfectants with pigeon feces.

KEY WORDS: Bangkok, Cryptococcus neoformans, disinfectant, pigeon droppings, susceptibility
\end{abstract}

doi: 10.1292/jvms.15-0594; J. Vet. Med. Sci. 78(3): 391-396, 2016

Cryptococcus neoformans is a basidiomycetous encapsulated yeast that can cause systemic and cutaneous cryptococcosis in humans and animals, particularly those that are immunosuppressed $[14,18]$. C. neoformans comprises three serotypes and two varieties: $C$. neoformans var. grubii (serotype A) and C. neoformans var. neoformans (serotype D and $\mathrm{AD}$ ), whereas the $C$. gattii group comprises two serotypes: $\mathrm{B}$ and $\mathrm{C}$ [3]. C. neoformans has a worldwide distribution and has been associated with a variety of environmental sources, such as soil, decayed wood and bird excreta, especially pigeon fecal droppings $[11,20]$. C. gattii typically is a cause of infections of the pulmonary and/or the central nervous system, and its favored ecological niche is in conditions of low moisture and low organic carbon content [8].

Cryptococcus neoformans variety grubii (serotype A) has been the major causative agent of cryptococcosis in Thai patients suffering from HIV/AIDS and has been shown to have a high prevalence in dove and pigeon excreta in Chiang Mai, Thailand [7, 25]. In general, C. neoformans is disseminated in the environment via fecal droppings of birds that can utilize ammonia as an assimilated nitrogen source within their digestive tracts [10]. Reports of cases of cryptococcosis have increased simultaneously with the increased number of HIV/AIDS patients: globally, estimated one million people

\footnotetext{
*Correspondence to: Prapasarakul, N., Department of Veterinary Microbiology, Faculty of Veterinary Science, Chulalongkorn University, Pathumwan District, Henri-Dunang Street, Bangkok, 10330 Thailand. e-mail: Nuvee.P@chula.ac.th

(C)2016 The Japanese Society of Veterinary Science

This is an open-access article distributed under the terms of the Creative Commons Attribution Non-Commercial No Derivatives (by-nc-nd) License $<$ http://creativecommons.org/licenses/by-nc-nd/4.0/>.
}

are infected each year, resulting in 620,000 deaths per year [19]. Consistent with this, in Thailand, there have been many cases of cryptococcosis in HIV/AIDS patients. Previously, the isolation rate of $C$. neoformans from pigeon fecal droppings in Thailand was found to be $9-24 \%, 16.4 \%$ and $10 \%$ in Bangkok and in Chiang Mai and Chonburi provinces, respectively $[9,24,25,28]$, and it was $45 \%$ in dove droppings in Chiang Mai [25]. Thus, areas of Bangkok with abundant wild pigeons may represent a risk of environmental contamination threatening the health of both immunocompromised and immunocompetent people. To date, the most contaminated districts in Bangkok have not been identified.

The disinfectants hydrogen peroxide, chlorine compounds, quaternary ammonium and potassium monopersulfate all potentially can serve as tools for reducing pathogen contamination. The use of either 1-2\% quaternary ammonium compound for $10 \mathrm{~min}$ or $1 \%$ sodium hypochlorite for $15 \mathrm{~min}$ has been recommended to kill $C$. neoformans by membrane disruption and cell lysis [22]. The microorganisms were also able to resist disinfectants, because of intrinsic factors, including their cell capsule and biofilm production [29], and external factors, such as organic matter level, that can affect the time required for inactivation and the guideline concentrations $[4,15,17]$. Surveillance of $C$. neoformans in public areas has been conducted often, but little is known about decontamination of bird droppings. The objectives of this study were to determine the occurrence and distribution of $C$. neoformans in pigeon droppings in different areas of Bangkok and to evaluate the efficacy of common disinfectants against $C$. neoformans mixed in organic matter compared to pure isolates. 


\section{MATERIALS AND METHODS}

Sample collection and isolation: A total of 164 samples of pigeon fecal droppings were collected from 11 districts in Bangkok during 2011-2012 (Fig. 1 and Supplementary Table 1). These included 97 pools of partially dried droppings and 67 pools of fresh droppings that were collected at temples and public parks with high pigeon populations. Approximately $5-10 \mathrm{~g}$ of pooled dropping from 1 square meter area were collected into sterile sealable plastic bags, stored at $4^{\circ} \mathrm{C}$ and cultured within $24 \mathrm{hr}$. Yeast isolation was performed according to a previous protocol [5]. Briefly, one part of the sample was suspended in 9 parts of peptone saline diluents contained within a selective mixture consisting of $0.04 \% \mathrm{w} / \mathrm{v}$ chloramphenicol (Sigma-Aldrich, Carlsbad, CA, U.S.A.), $0.02 \% \mathrm{w} / \mathrm{v}$ of streptomycin sulfate (Sigma-Aldrich) and $0.01 \% \mathrm{w} / \mathrm{v}$ of biphenyl (Alfa Aesar, Lancashire, U.K.). The suspension was incubated for $24 \mathrm{hr}$ at $37^{\circ} \mathrm{C}$ with agitation and then diluted ten-fold from $10^{\circ}$ to $10^{-5}$. A $100 \mu l$ volume of supernatant was inoculated on Sabouraud dextrose agar (SDA) and on caffeic acid ferric citrate agar (CFCA) (SigmaAldrich) [31] and incubated at $37^{\circ} \mathrm{C}$ for 3-7 days. Suspected colonies were observed for typical features comprising creamcolored smooth mucoid colonies on SDA and brown colonies on CFAC. The presence of the organisms was confirmed by Indian ink staining, a urease test and sugar assimilations using sucrose, trehalose, lactose, maltose, galactose and dextrose [1]. C. neoformans CN 175 was used as the control strain.

Molecular identification and serotyping: Genomic DNA was extracted by the Wizard ${ }^{\circledR}$ Genomic DNA purification Kit (Promega, Madison, WI, U.S.A.) with a $0.5 \mathrm{~mm}$ diameter glass bead (Sigma-Aldrich). Briefly, the strains were grown on yeast extracts peptone dextrose broth (YPDB) at $37^{\circ} \mathrm{C}$ with agitation for $24 \mathrm{hr}$ and then centrifuged for $5 \mathrm{~min}$ at $2,600 \mathrm{rpm}$. The packed cells were collected and re-suspended in $300 \mu \mathrm{l}$ of lysis buffer (1:1) with $300 \mathrm{mg}$ glass beads. The samples were incubated at $-80^{\circ} \mathrm{C}$ for $15 \mathrm{~min}$ and vortexed vigorously for $45 \mathrm{~min}$ three times before centrifuging at $15,000 \mathrm{rpm}$ for $5 \mathrm{~min}$. The aqueous phase was extracted using the purification kit according to the manufacturer's instructions (Promega).

A multiplex polymerase chain reaction (M-PCR) specific to $C$. neoformans and $C$. gattii was performed using primer sets: CNa-70S (5'-ATTGCGTCCACCAAGGAGCTC3') / CNa-70A (5'-ATTGCGTCCATGTTACGTGGC-3') and CNb-49s (5'- ATTGCGTCCATGTTACGTGGC-3') /CNb49A (5'-ATTGCGTCCATGTTACGTGGC-3'), respectively. The PCR conditions followed a previously described protocol [16]. For serotyping, the approved multiplex PCR using four primer pairs specific to the laccase gene fragment ( $L A C$ 1) encoding capsule membrane variation was performed as previously described [16]. The PCR conditions were an initial denaturation for $3 \mathrm{~min}$ at $94^{\circ} \mathrm{C}$, followed by 35 cycles of denaturation $\left(94^{\circ} \mathrm{C}\right.$ for $\left.30 \mathrm{sec}\right)$, annealing $\left(47^{\circ} \mathrm{C}\right.$ for $\left.1 \mathrm{~min}\right)$ and extension $\left(72^{\circ} \mathrm{C}\right.$ for $\left.1.5 \mathrm{~min}\right)$, and this was followed by final extension ( $72^{\circ} \mathrm{C}$ for $\left.7 \mathrm{~min}\right)$. C. neoformans var. grubii, WM148, C. neoformans, WM629 and C. neoformans var. grubii/ var. neoformans hybrid, WM628 were used as the

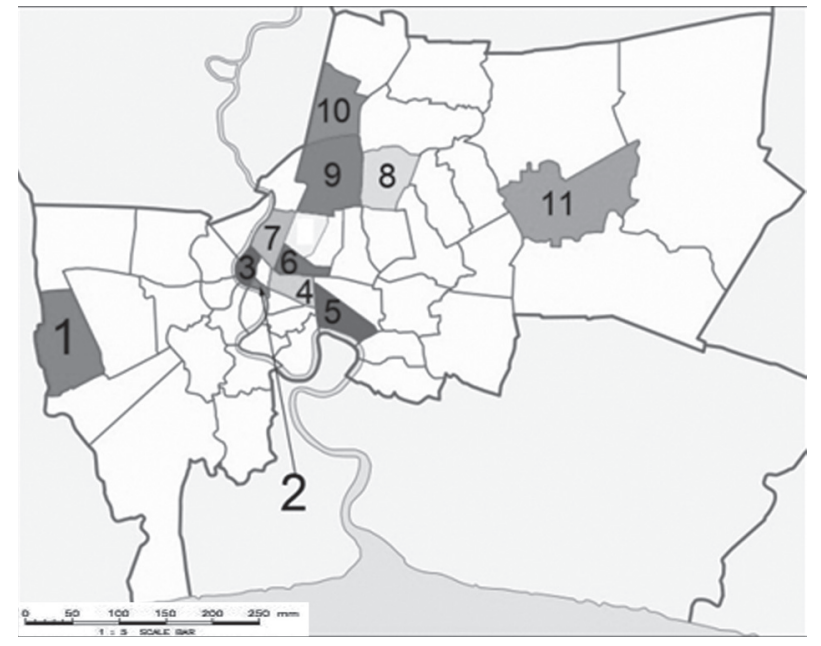

Fig. 1. Presence on the Bangkok map of 11 districts where pigeon droppings were collected, represented by colors and numbers (1=Nong Khaem; 2=Samphanthawong; 3=Phra Nakhon; 4=Pathum Wan; 5=Khlong Toei; 6=Ratchathewi; 7=Dusit; 8=Lat Phrao; 9=Chatuchak; 10=Lak si and 11=Min Buri). Only districts 1,5 and 8 yielded positive samples.

control strains.

Fungicidal efficacy evaluation: Three biocides: Product A $[50 \% \mathrm{w} / \mathrm{w}$ potassium peroxymonosulphate, 5\% w/w sodium dichloroisocyanurate and $15 \% \mathrm{w} / \mathrm{w}$ sulphamic acid] (Elanco, Saligo, Ireland), Product B [99.9\% sodium hypochlorite] (Lab Valley, Bangkok, Thailand) and Product C $[10.8 \%$ N-benzyl-N-dodecyl-N,N-dimethyl-ammonium chloride/N-benzyl-N,N-dimethyl-N-tetradecyl-ammonium chloride; benzalkonium chloride] (Laboratoire Huckert's International, Wavre, Belgium) were tested for their efficacies against pure isolates of $C$. neoformans and $C$. neoformans mixed in sterile pigeon droppings. A total of 8 strains comprising five $C$. neoformans strains: KT1/12, LP1/12, LP2/12, NK1/12 and NK2/12, obtained from pigeon dropping, one parrot strain (PR1/12), one feline strain (FL1/12) and one strain isolated from a human (WM148) were prepared on $\mathrm{SDA}$ at $37^{\circ} \mathrm{C}$ for 3 days. The yeast cells were harvested and suspended in Sabouraud dextrose broth and then adjusted to 0.1 at $\mathrm{OD} 530 \mathrm{~nm}\left(1-5 \times 10^{6}\right.$ cells $\left./ \mathrm{m} l\right)$. For sterile organic matter preparation, a total of $20 \mathrm{~g}$ pigeon droppings were mixed with $80 \mathrm{~m} l$ sterile deionized water and then sterilized in an autoclave at $121^{\circ} \mathrm{C}$ for $15 \mathrm{~min}$ [13].

The protocol was modified from the dilution-neutralization method according to the Europäische NORM 1656 (EN 1656) recommendation (European Committee form Standardization, 2000) [26]. All disinfectants were diluted with sterile deionized water at the recommended concentration. Solutions of the three chemical disinfectant preparations were prepared at final serial two-fold concentrations from $1 \%$ to $0.03 \%$ for the pure C. neoformans test and from $2 \%$ to $0.06 \%$ for the $C$. neoformans mixed in sterile pigeon droppings test. For evaluation of disinfectant in organic matter, $1 \mathrm{~m} l$ pure $C$. neoformans suspension mixed with $1 \mathrm{~m} l$ sterile 
Table 1. Sampling data including condition of the pigeon droppings, sun exposure and location, and risk in relation to the occurrence of Cryptococcus neoformans

\begin{tabular}{lcc}
\hline \multicolumn{1}{c}{ Sources } & Number of positive/total sample & $P$-value \\
\hline Condition of pigeon droppings & & \\
$\quad$ - Fresh & $1 / 67$ & 0.001 \\
- Dried & $17 / 97$ & \\
\hline Sun explosure & & \\
$\quad$ - Direct sunlight & $13 / 99$ & 0.204 \\
- Shaded & $5 / 65$ & \\
\hline Location & & \\
- Outdoors & $10 / 110$ & 0.200 \\
- Indoors & $8 / 54$ & \\
\hline
\end{tabular}

a) $P \leq 0.05$ is considered to be statistically significant by Chi-square.

pigeon droppings was filled up to $10 \mathrm{~m} l$ in each dilution of each disinfectant (in hard water prepared according to the EN1656 standard) and shaken thoroughly. The mixture was incubated at room temperature for $10 \mathrm{sec}, 30 \mathrm{sec}$, and 1, 3, $5,10,15$ and $30 \mathrm{~min}$ of exposure time. Afterward, $1 \mathrm{ml}$ of the suspension was transferred into $9 \mathrm{~m} l$ of Dey/Engley neutralizing broth (Sigma-Aldrich) containing 0.5\% pancreatic digest of casein, $0.25 \%$ yeast extract, $1 \%$ dextrose, $0.1 \%$ sodium thioglycollate, $0.6 \%$ sodium thiosulfate, $0.25 \%$ sodium bisulfite, $0.5 \%$ polysorbate $80,0.7 \%$ lecithin and $0.002 \%$ bromcresol purple, and then incubated at room temperature for $5 \mathrm{~min}$. Then, $100 \mu \mathrm{l}$ of each suspension was cultured onto SDA by the pour plate method and incubated at $37^{\circ} \mathrm{C}$ for 3 days. Colony-forming units were counted to determine the number of yeast that survived the disinfection test. At the same time, the former protocol and interpretation were determined with $1 \mathrm{~m} l$ pure $C$. neoformans without sterile pigeon droppings mixed with $9 \mathrm{~m} l$ disinfectant and assigned as group 2. The non-antimicrobial effect of neutralizer was confirmed by using the standard protocol [26].

Statistical analysis: Yeast enumeration was performed with 20-200 colonies grown on the agar. C. neoformans distribution associated with different factors including dropping condition, indoor and outdoor location and sun exposure (Table 1) were analyzed by the Chi-square test using SPSS version 17, (IBM., Manhattan, NY, U.S.A.). A value of $P \leq 0.05$ was considered to be statistically significant. The bacteriocidal efficacies of the three disinfectants at different dilutions and time-kill were compared by analysis of variance.

\section{RESULTS}

Of the 164 pools of samples analyzed, 18 (11\%) were positive for $C$. neoformans by both selective culture and multiplex PCR. All isolates grew at $37^{\circ} \mathrm{C}$, and all showed a mucopolysaccharide capsule-like appearance as presented by Indian ink staining. The occurrence and distribution of C. neoformans in Bangkok are shown in Table 1, Fig. 1 and Supplementary Table 1, with isolates only obtained from the districts of Nongkhaem (No 1), Latphrao (No. 5), and Khlongtoei (No. 8).
The number of yeast cells within one gram of feces ranged from 0.94 to $2.60 \times 10^{5} \mathrm{CFU} / \mathrm{g}$ with an average of $(1.79 \pm 0.54) \times 10^{5} \mathrm{CFU} / \mathrm{g}$. For species identification, all product sizes were the same as the $C$. neoformans specific product at $695 \mathrm{bp}$, as well as those of the control strain of $C$. neoformans. For serotyping, all strains were grouped in $C$. neoformans var. grubii (serotype A). As shown in Table 1, 17 positive samples were obtained from 97 dried pigeon droppings samples, whereas only one was obtained from 67 fresh samples $(P<0.001)$. There was no difference associated with the location (indoors or outdoors) or sun exposure.

The susceptibilities of the pure C. neoformans isolates and the yeast mixed with sterile pigeon droppings to the three disinfectants are shown in Figs. 2 and 3. Regarding the endpoint of the fungicidal effect, Products A and B could kill all $C$. neoformans cells at $1 \%$ within 1 min while $0.50 \%$ killed within 3 min, while $C$. neoformans mixed with sterile pigeon droppings was completely eradicated at $2 \%$ within 3 and 1 min for Products A and B, respectively. Product C could rapidly kill all $C$. neoformans at $0.5 \%$ and still was effective at $0.03 \%$ for $1 \mathrm{~min}$, while the yeast in organic matter was rapidly killed at $1 \%$ and the product maintained its efficiency to $0.062 \%$ within $30 \mathrm{~min}$. All 8 tested strains from different sources showed similar results for effective concentration and time exposures.

\section{DISCUSSION}

This study was not the first surveillance in Bangkok, but it is the most recent for this capital city. Eleven districts were studied to represent a wide cross section of the city. Temples and public parks were prioritized areas due to their high density of pigeon flocks that were likely to represent the highest risk of contamination to the public. Overall, the occurrence of $C$. neoformans $(11 \%)$ was at a lower percentage than reports for Chiang Mai, Thailand (16.4-45\%), Seoul, Korea $(25 \%)$ and Grand Canary Island $(24.45 \%)$ [2, 21, 25]. In Bangkok, the distribution was focal, and of the three positive districts, the rate was substantially higher in Nongkhaem $(9 / 16,56.2 \%)$ and Latphrao $(7 / 16,43.7 \%)$ than in Khlongtoei $(2 / 15,13.3 \%)$. The reason for the differences in prevalence 


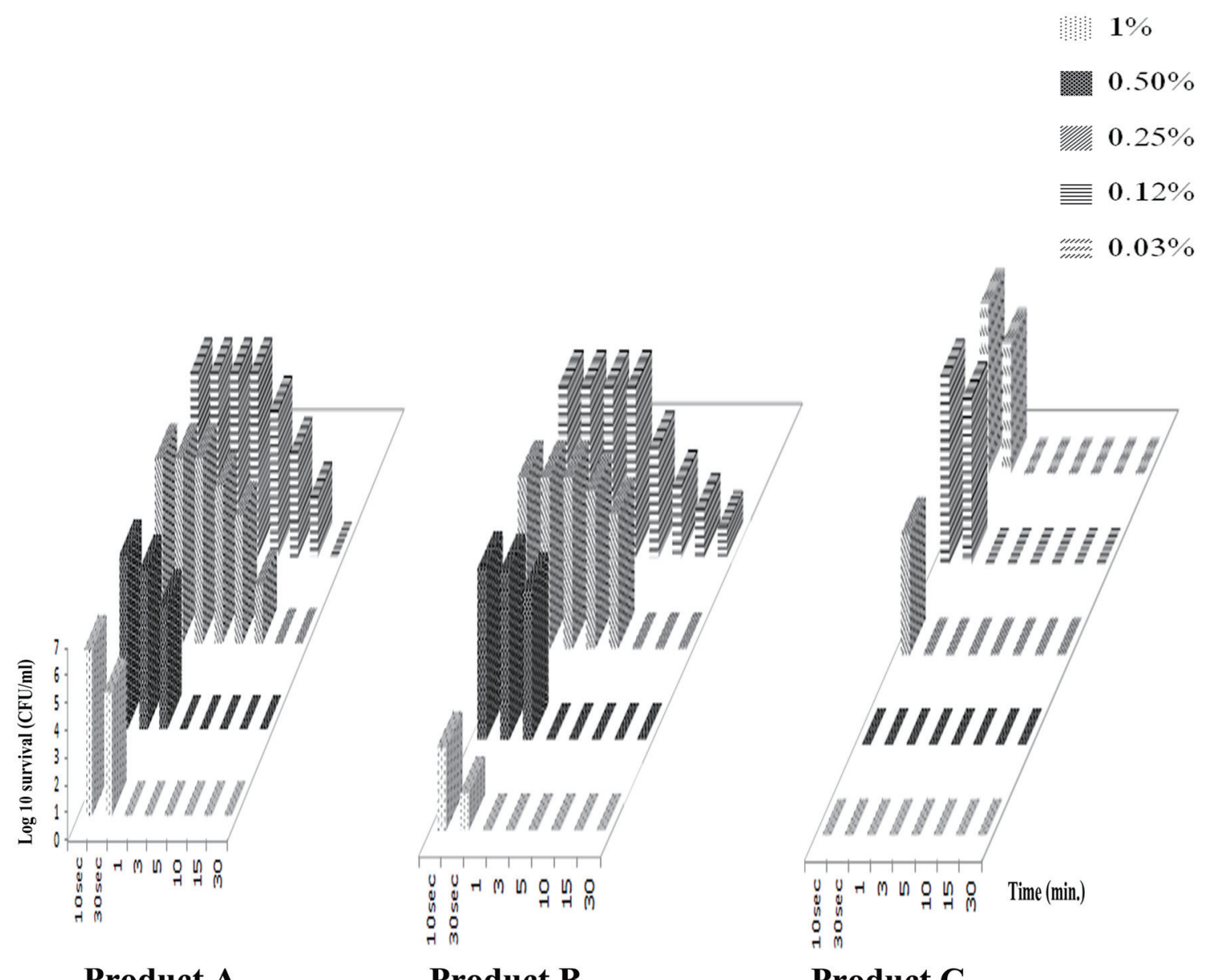

Fig. 2. Comparison of survival rate of the pure C. neoformans isolates after exposed to different concentrations of the three disinfectants for different times (see text for identification of the products).

is uncertain, but might reflect the habitat of bird flocks and their feed type in each area. However, bird migration also may contribute to the transmission of infection. In our study, the average number of yeast contamination in dropping was about 10 times less than in a previous report [30] and would presumably represent a lower risk for transmission.

Previously, serotype A was the most common group found in Bangkok as well as in Seoul, Korea [2], but only one human clinical isolate in Chiang Mai was serotype AD [25]. Genetic similarities recently have been shown between isolates from animal sources and human patients in Thailand [6]. This study strongly confirmed that dried droppings are more likely to contain yeast spores than fresh droppings [2]. The incidence of $C$. neoformans in the environment previously has been reported to depend on abiotic components, including the presence of protein, carbohydrate and creatinine, and physical conditions including light, temperature and moisture $[4,15,17]$.

The inoculum concentration used for disinfectant evaluation was similar to the average number of organisms contained in bird droppings and also was within the acceptable range according to the standard protocol. Therefore, this testing regimen should mimic the situation in the environment. This study selected strains from various sources and locations to reduce confounding factors arising from differences in $C$. neoformans virulence and resistance, such as cell wall thickness, the presence of a capsule, melanin and biofilm production [15]. However, all tested strains showed a strong consistence in their susceptibility to all disinfectants. In relation to the concentration of each disinfectant, the starting concentration ( $1 \%$ ) for the pure C. neoformans isolates and $(2 \%)$ for yeast mixed with sterile pigeon droppings were chosen because of the manufacturers' recommendations, and a two-fold reducing concentration was performed until the endpoint of the time-kill and doses of pure inoculum were reached. Sterile pigeon droppings were designed to represent organic matter that may interfere with the efficacy of the disinfectants [27].

Products A and B were effective in the range of the manufacturers' recommendations. At the same time, product $\mathrm{C}$ was the strongest fungicidal disinfectant for $C$. neoformans in pigeon droppings. This report is the first making recom- 


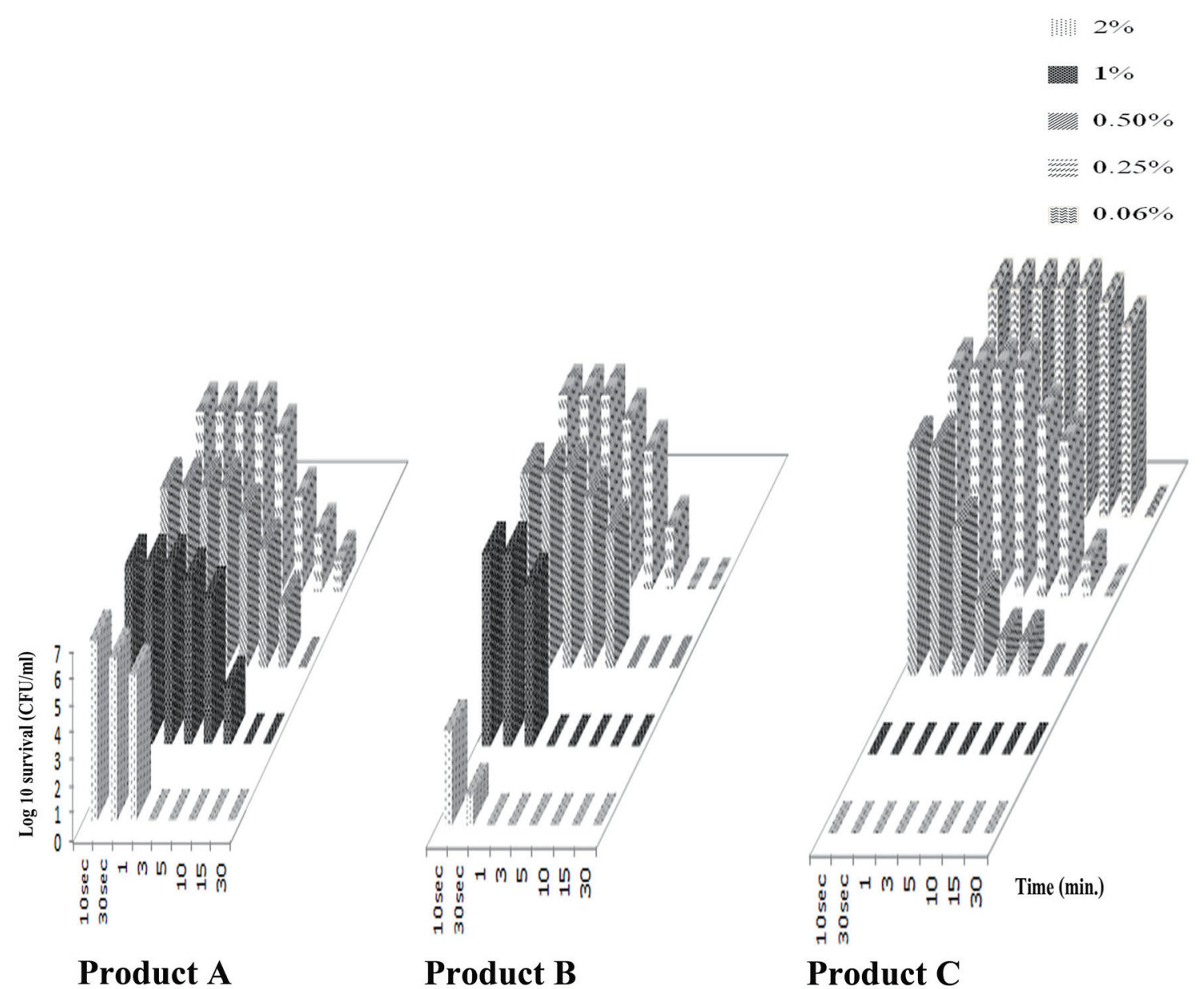

Fig. 3. Comparison of survival rate of C. neoformans mixed in sterile pigeon droppings and exposed to different concentrations of the three disinfectants for different times.

mendations for suitable concentrations and time exposure to achieve fungicidal effect against $C$. neoformans in pigeon droppings. The efficacies of Products A and B, both chloride releasing agents, are reduced by organic matter, such as soil, feces and blood [12, 15], as well as by chlorhexidine [23]. An increase in duration of exposure can increase their efficacies in practical use. Product $\mathrm{C}$ is a cationic detergent that is a quaternary ammonium compound used for a variety of clinical purposes [15]. This derivative was the most outstanding agent and did not show reduced efficacy in organic matter with any time-kill effect (at $2 \%$ to $0.062 \%$ ). In conclusion, C. neoformans var. grubii (serotype A) was found at a variable but sometimes very high prevalence (13-56\%) in pigeon droppings in only three of 11 Bangkok districts (Nong Kham, Khlong Toei and Lat Phrao). To complete eradication of $C$. neoformans in organic matters, increase of time-kill and concentration-kill may be an option in the guidance of disinfectant preparation. The quaternary ammonium compound was the most effective against $C$. neoformans from all sources in this study and may be recommended for decontamination in an endemic area.
ACKNOWLEDGMENTS. This work was supported by the 90th Anniversary of Chulalongkorn University Fund (Ratchadaphiseksomphot Endowment Fund, No.23 (1/2014). The authors would like to thank Assoc. Prof. Dr. Ariya Chindamporn and Assist. Prof. Dr. Sirilak Surachetpong for providing the human and cat strains, respectively and the Center of Excellence for Emerging and Re-emerging Infectious Diseases in Animals for a student research scholarship and to Professor David Hampson, Murdoch University, Western Australia and to the Office of Research Affairs, Chulalongkorn University for assistance during manuscript preparation.

\section{REFERENCES}

1. Cafarchia, C., Romito, D., Iatta, R., Camarda, A., Montagna, M. T. and Otranto, D. 2006. Role of birds of prey as carriers and spreaders of Cryptococcus neoformans and other zoonotic yeasts. Med. Mycol. 44: 485-492. [Medline] [CrossRef]

2. Chee, H. Y. and Lee, K. B. 2005. Isolation of Cryptococcus neoformans var. grubii (serotype A) from pigeon droppings in Seoul, Korea. J. Microbiol. 43: 469-472. [Medline] 
3. Chowdhary, A., Rhandhawa, H. S., Prakash, A. and Meis, J. F. 2012. Environmental prevalence of Cryptococcus neoformans and Cryptococcus gattii in India: an update. Crit. Rev. Microbiol. 38: 1-16. [Medline] [CrossRef]

4. Cremieux, A. 1986. Factors affecting the bactericidal action of disinfectants. Implications for selection of resistant strains. Drugs Exp. Clin. Res. 12: 899-903. [Medline]

5. Hedayati, M. T., Mayahi, S., Fakhar, M., Shokohi, T. and Majidi, M. 2011. Cryptococcus neoformans isolation from swallow (Hirundo rustica) excreta in Iran. Rev. Inst. Med. Trop. Sao Paulo 53: 125-127. [Medline] [CrossRef]

6. Kaocharoen, S., Ngamskulrungroj, P., Firacative, C., Trilles, L., Piyabongkarn, D., Banlunara, W., Poonwan, N., Chaiprasert, A., Meyer, W. and Chindamporn, A. 2013. Molecular epidemiology reveals genetic diversity amongst isolates of the Cryptococcus neoformans/C. gattii species complex in Thailand. PLoS Negl. Trop. Dis. 7: e2297. [Medline] [CrossRef]

7. Khayhan, K., Hagen, F., Pan, W., Simwami, S., Fisher, M. C., Wahyuningsih, R., Chakrabarti, A., Chowdhary, A., Ikeda, R., Taj-Aldeen, S. J., Khan, Z., Ip, M., Imran, D., Sjam, R., Sriburee, P., Liao, W., Chaicumpar, K., Vuddhakul, V., Meyer, W., Trilles, L., Van Iersel, L. J., Meis, J. F., Klaassen, C. H. and Boekhout, T. 2013. Geographically structured populations of Cryptococcus neoformans variety grubii in Asia correlate with HIV status and show a clonal population structure. PLoS ONE 8: e72222. [Medline] [CrossRef]

8. Kidd, S. E., Chow, Y., Mak, S., Bach, P. J., Chen, H., Hingston, A. O., Kronstad, J. W. and Bartlett, K. H. 2007. Characterization of environmental sources of the human and animal pathogen Cryptococcus gattii in British Columbia, Canada, and the Pacific Northwest of the United States. Appl. Environ. Microbiol. 73: 1433-1443. [Medline] [CrossRef]

9. Kuroki, M., Phichaichumpon, C., Yasuoka, A., Chiranairadul, P., Chosa, T., Sirinirund, P., Miyazaki, T., Kakeya, H., Higashiyama, Y., Miyazaki, Y., Ishida, Y. and Kohno, S. 2004. Environmental isolation of Cryptococcus neoformans from an endemic region of HIV-associated cryptococcosis in Thailand. Yeast 21: 809-812. [Medline] [CrossRef]

10. Lee, I. R., Chow, E. W., Morrow, C. A., Djordjevic, J. T. and Fraser, J. A. 2011. Nitrogen metabolite repression of metabolism and virulence in the human fungal pathogen Cryptococcus neoformans. Genetics 188: 309-323. [Medline] [CrossRef]

11. Leite, D. P. Jr., Amadio, J. V., Martins, E. R., Simoes, S. A., Yamamoto, A. C., Leal-Santos, F. A., Takahara, D. T. and Hahn, R. C. 2012. Cryptococcus spp. isolated from dust microhabitat in Brazilian libraries. J. Occup. Med. Toxicol. 7: 11. [Medline] [CrossRef]

12. Levy, S. B. 1992. Active efflux mechanisms for antimicrobial resistance. Antimicrob. Agents Chemother. 36: 695-703. [Medline] [CrossRef]

13. Lobova, D. and Cizek, A. 2004. Bactericidal efficacy of two disinfectants against Brachyspira hyodysenteriae and one feed supplement against B. hyodysenteriae and B. pilosicoli. Vet. Med. Czech. 49: 156-160.

14. Maesaki, S., Sasaki, E., Kakeya, H., Noda, T., Kawamura, S., Mitsutake, K., Tomono, K., Tashiro, T. and Kohno, S. 1998. Severe mycosis-factors with fungus and host. Nihon Ishinkin Gakkai Zasshi 39: 193-197. [Medline] [CrossRef]

15. McDonnell, G. and Russell, A. D. 1999. Antiseptics and disinfectants: activity, action, and resistance. Clin. Microbiol. Rev. 12: 147-179. [Medline]

16. Mseddi, F., Sellami, A., Jarboui, M. A., Sellami, H., Makni, F. and Ayadi, A. 2011. First environmental isolations of Cryptococcus neoformans and Cryptococcus gattii in Tunisia and review of published studies on environmental isolations in Africa. Mycopathologia 171: 355-360. [Medline] [CrossRef]

17. Nett, J. E., Guite, K. M., Ringeisen, A., Holoyda, K. A. and Andes, D. R. 2008. Reduced biocide susceptibility in Candida albicans biofilms. Antimicrob. Agents Chemother. 52: 3411-3413. [Medline] [CrossRef]

18. O’Brien, C. R., Krockenberger, M. B., Wigney, D. I., Martin, P. and Malik, R. 2004. Retrospective study of feline and canine cryptococcosis in Australia from 1981 to 2001: 195 cases. Med. Mycol. 42: 449-460. [Medline] [CrossRef]

19. Park, B. J., Wannemuehler, K. A., Marston, B. J., Govender, N., Pappas, P. G. and Chiller, T. M. 2009. Estimation of the current global burden of cryptococcal meningitis among persons living with HIV/AIDS. AIDS 23: 525-530. [Medline] [CrossRef]

20. Quintero, E., Castaneda, E. and Ruiz, A. 2005. Environmental distribution of Cryptococcus neoformans in the department of Cundinamarca-Colombia. Rev. Iberoam. Micol. 22: 93-98. [Medline] [CrossRef]

21. Rosario, I., Soro, G., Deniz, S., Ferrer, O., Acosta, F., Padilla, D. and Acosta, B. 2010. Presence of C. albidus, C. laurentii and C. uniguttulatus in crop and droppings of pigeon lofts (Columba livia). Mycopathologia 169: 315-319. [Medline] [CrossRef]

22. Rotmistrov, M. N., Vasilevskaia, I. A., Kulik, G. V., Shpilevaia, L. D. and Gorbonos, T. V. 1970. Study of antifungal properties of ammonium caprylate. Mikrobiol. Zh. 32: 780-787. [Medline]

23. Russell, A. D. and Day, M. J. 1993. Antibacterial activity of chlorhexidine. J. Hosp. Infect. 25: 229-238. [Medline] [CrossRef]

24. Soogarun, S., Wiwanitkit, V., Palasuwan, A., Pradniwat, P., Suwansaksri, J., Lertlum, T. and Maungkote, T. 2006. Detection of Cryptococcus neoformans in bird excreta. Southeast Asian J. Trop. Med. Public Health 37: 768-770. [Medline]

25. Sriburee, P., Khayhan, S., Khamwan, C., Panjaisee, S. and Tharavichitkul, P. 2004. Serotype and PCR-fingerprints of clinical and environmental isolates of Cryptococcus neoformans in Chiang Mai, Thailand. Mycopathologia 158: 25-31. [Medline] [CrossRef]

26 Standardization ECF. 2000. European Standard EN1656. Chemical disinfectants and antiseptics-Quantitative suspension test for the evaluation of bactericidal activity of chemical disinfectants and antiseptics used in veterinary field-Test method and requirements (phase2/step1).

27. Stringfellow, K., Anderson, P., Caldwell, D., Lee, J., Byrd, J., Mcreynolds, J., Carey, J., Nisbet, D. and Farnell, M. 2009. Evaluation of disinfectants commonly used by the commercial poultry industry under simulated field conditions. Poult. Sci. 88: 1151-1155. [Medline] [CrossRef]

28. Tangwattanachuleeporn, M., Somparn, P., Poolpol, K., Gross, U., Weig, M. and Bader, O. 2013. Prevalence and antifungal susceptibility of Cryptococcus neoformans isolated from pigeon excreta in Chon Buri Province, Eastern Thailand. Med. Mycol. J. 54: 303-307. [Medline] [CrossRef]

29. Théraud, M., Bedouin, Y., Guiguen, C. and Gangneux, J. P. 2004. Efficacy of antiseptics and disinfectants on clinical and environmental yeast isolates in planktonic and biofilm conditions. J. Med. Microbiol. 53: 1013-1018. [Medline] [CrossRef]

30. Tripp, C., Ruiz, A. and Bulmer G. S. 1981. Culture of Cryptococcus neoformans in the nonencapsulated state. Mycopathology 76: 129-131.

31. Vidotto, V., Aoki, S., Ponton, J., Quindos, G., Koga-Ito, C. Y. and Pugliese, A. 2004. A new caffeic acid minimal synthetic medium for the rapid identification of Cryptococcus neoformans isolates. Rev. Iberoam. Micol. 21: 87-89. [Medline] 